\title{
Panretinal photocoagulation in central retinal vein occlusion: a randomised controlled clinical study
}

\author{
L. LAATIKAINEN, E. M. KOHNER, D. KHOURY, AND R. K. BLACH \\ From the Retinal Diagnostic Unit, Moorfields Eye Hospital, London
}

SUMMARY A randomised controlled study of photocoagulation compared with no treatment in central retinal vein occlusion is reported. Forty-eight patients were allocated into treated and control groups by a random procedure 3 months after their first visual symptoms. For the analysis they were subdivided into (1) ischaemic type, and (2) hyperpermeability-response macular-oedema type of central retinal vein occlusion.

In neither group did treatment confer benefit as far as visual acuity was concerned. However, iris, disc, and retinal neovascularisation improved after treatment in the ischaemic group. In addition none of the treated patients progressed to neovascular glaucoma. Macular-oedema improved in treated patients with the hyperpermeability response, but the visual field was affected and atrophic changes at the macula precluded visual improvement.

It is concluded that photocoagulation should be used only to prevent complications in the ischaemic type of central retinal vein occlusion. It does not appear to be of value in the hyperpermeability group.

Photocoagulation has been shown to be effective in the treatment of both macular oedema and neovascularisation in diabetic retinopathy. It is therefore reasonable to assume that similar results can be achieved in retinal vein occlusion, where macular oedema and new vessel formation are common complications. There are several reports indicating 'good results' (Zweng et al., 1974; Theodossiadis et al., 1974; Freyler and Nichorlis, 1974; Wetzig and Thatcher, 1974; Oosterhuis and Sedney, 1975; Sedney, 1976), but none of these was a randomised controlled clinical study. In order to determine the exact place of photocoagulation in the treatment of central retinal vein occlusion (CRVO) a randomised controlled trial was carried out at Moorfields Eye Hospital during 1975-7. The results of this study are presented in this communication.

\section{Patients and methods}

\section{PATIENTS}

All patients with recent CRVO (less than 3 months' duration of symptoms) referred to the Retinal Diagnostic Unit at Moorfields Eye Hospital in 1975 were considered for the trial. The patients were assessed and followed up without treatment until

Address for reprints: Dr E. M. Kohner, Royal Postgraduate Medical School, Hammersmith Hospital, London W12
3 months after initial visual symptoms. At the 3-month examination patients whose visual acuity was $6 / 24$ or worse entered the study provided they did not have neovascular glaucoma or other eye disease affecting vision and precluding treatment, and provided they agreed to randomisation.

Randomisation was by the use of pre-prepared sealed envelopes which indicated whether an eye was for treatment by photocoagulation or remained untreated, i.e., control. No other therapy for vein occlusion was given to any of the patients, but glaucoma and medical conditions were treated as required. There were 24 treated and 24 control patients. The mean age of the patients was 62 years (range 44-79 years) in the treated and 61.6 years (range 36-79 years) in the untreated group.

The patients were followed up for at least 1 year after entering the trial whenever possible. Five patients were not followed up for the required time. Two died, 4 and 10 months after entering the trial, 1 left the country, and 2 defaulted from follow-up.

During the course of the study the initial scheme was slightly modified so that eyes with considerable capillary closure were entered into the trial as soon as the first fluorescein angiogram became available, i.e., before 3 months expired.

Prior to analysis patients were subdivided into two subgroups according to the main cause of visual loss as revealed by fluorescein angiography. The 
groups were: (1) Ischaemic group with predominant retinal capillary closure (12 treated and 11 control patients). (2) Predominant macular oedema characterised by only small areas of capillary non-perfusion at the posterior pole and dilated capillaries with marked leakage (hyperpermeability response). There were 12 treated and 13 control patients.

\section{METHODS}

All patients had a full medical and ophthalmological examination, including visual acuity, slit-lamp examination of the anterior segment, applanation tonometry, gonioscopy, Goldmann perimetry, direct and indirect ophthalmoscopy, fundus photography, and fluorescein angiography. In most cases iris angiography was also performed. Follow-up examination was at 3 months, 1 month after entering the trial and 3 monthly thereafter until 1 year, whenever possible. At every visit visual acuity and intraocular pressure as well as changes in the iris and fundus were recorded, and photography was repeated. The visual field was checked once after treatment.

For treatment the O'Malley Log II xenon arc photocoagulator was used. After retrobulbar anaesthesia of $1.5 \mathrm{ml} 2 \%$ lignocaine hydrochloride approximately 400 burns (range $250-550$ ) of $4.5^{\circ}$ spot size were applied as a $360^{\circ}$ panretinal photocoagulation, leaving the macular area inside the temporal vascular arcade untreated. All patients were treated as outpatients in one or two sessions. In 7 patients the treatment was completed by argon laser burns (Coherent Radiation Model 800 laser).

\section{Results}

\section{VISUAL ACUITY}

The visual acuity results are shown in Figs. 1 and 2 . Visual outcome in the ischaemic group was poor (Fig. 1a, $b$ ). Among the treated patients 2 improved by 2 lines on the Snellen chart, 4 remained unchanged, 5 deteriorated, 1 to no perception of light. In the control group 1 of 11 improved by 4 lines, one by 2 lines, 5 remained unchanged, and 4 deteriorated, 1 to no perception of light. The one untreated patient who improved re-established drainage of the inferior temporal quadrant with improvement of the perifoveal capillary circulation.

Visual outcome in the macular oedema group was also poor. In all treated and untreated eyes remained within one line of the initial visual acuity (Fig. $2 a, b$ ). The difference between the treated and untreated eyes was not significant.

\section{VISUAL FIELDS}

In the ischaemic group with extensive capillary closure marked constriction of the visual field was

\section{ISCHAEMIC TYPE CRVO}

$$
\text { TREATED EYES }
$$

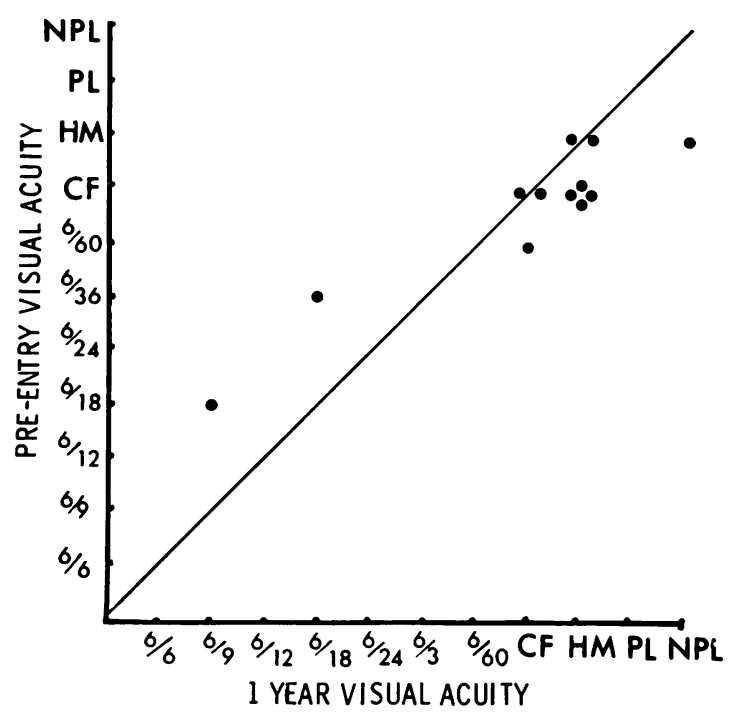

Fig. 1 a Pretreatment versus 1 year visual acuity in patients with predominant capillary closure who had treatment by photocoagulation

$C F=$ counting fingers. $H M=$ hand movements. $P L=$ perception of light. $N P L=$ no perception of light

\section{ISCHAEMIC TYPE CRVO} UNTREATED EYES

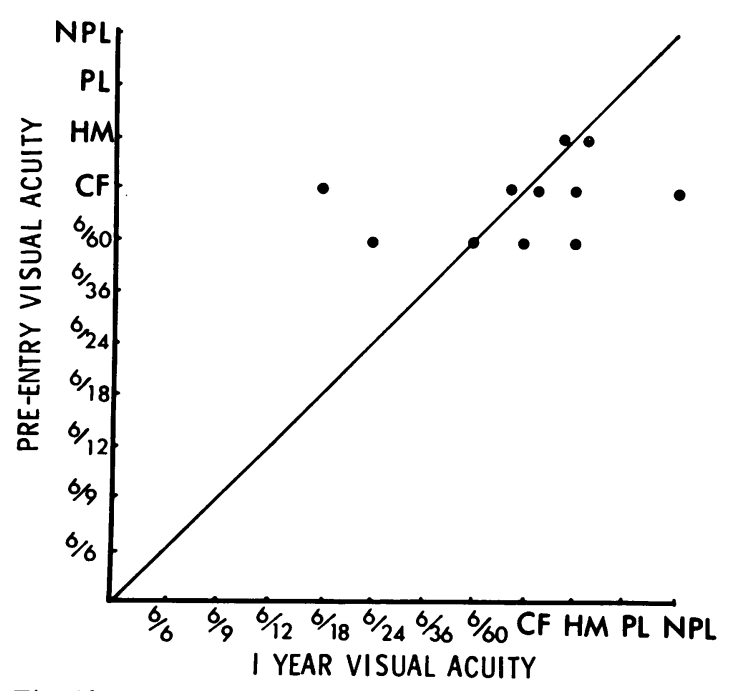

Fig. $1 b$ Pre-entry versus 1 year visual acuity in patients with predominant capillary closure who had no treatment 
common finding (Fig. 3) (although in a few cases normal peripheral isopter was found using a large bright test object (Fig. 4a)). No improvement of the visual fields was found in any of the cases if the macula was affected. In most instances the visual

\section{HYPER-PERMEABILITY TYPE OF CRVO \\ TREATED EYE}

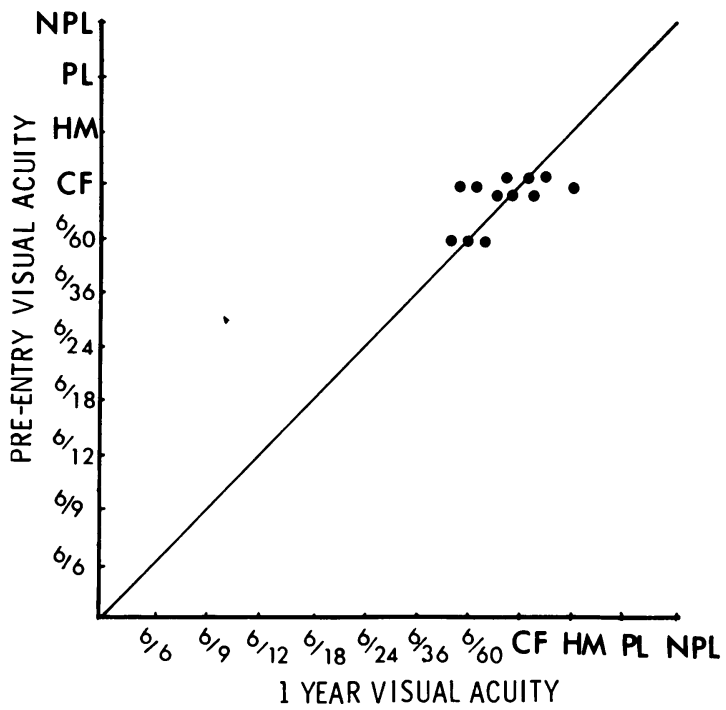

Fig. $2 a$ Pretreatment versus 1 year visual acuity in patients with the hyperpermeability, macular-oedema response, who had treatment by photocoagulation field deteriorated owing to complications described later or to post-treatment retinal scarring (Fig. 4b).

In the macular oedema group relative scotomas of various sizes were found in all cases studied (Fig. $5 a, 6 a$ ). In some eyes enlargement of the blind spot and/or constriction of the peripheral field as com-

\section{HYPER-PERMEABILITY TYPE OF CRVO UNTREATED EYE}

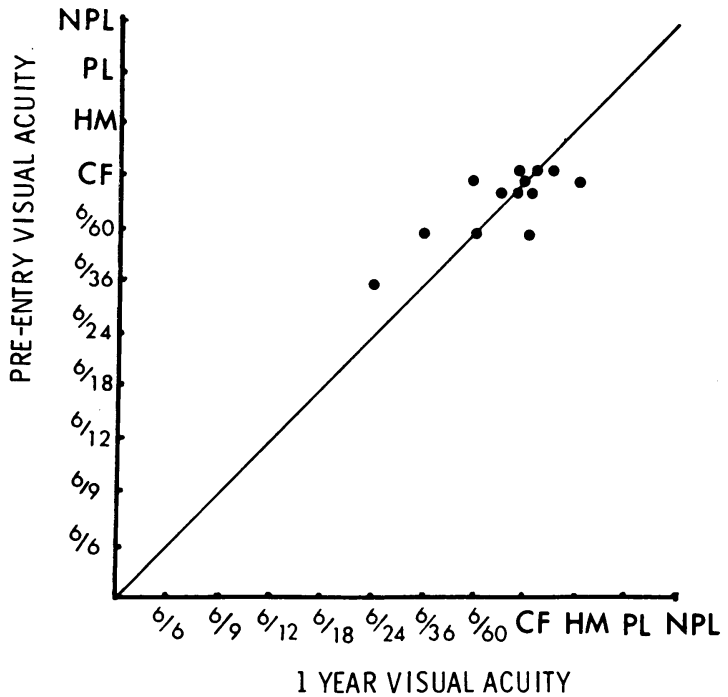

Fig. $2 b$ Pre-entry versus 1 year visual acuity in patients with the hyperpermeability response who had no treatment

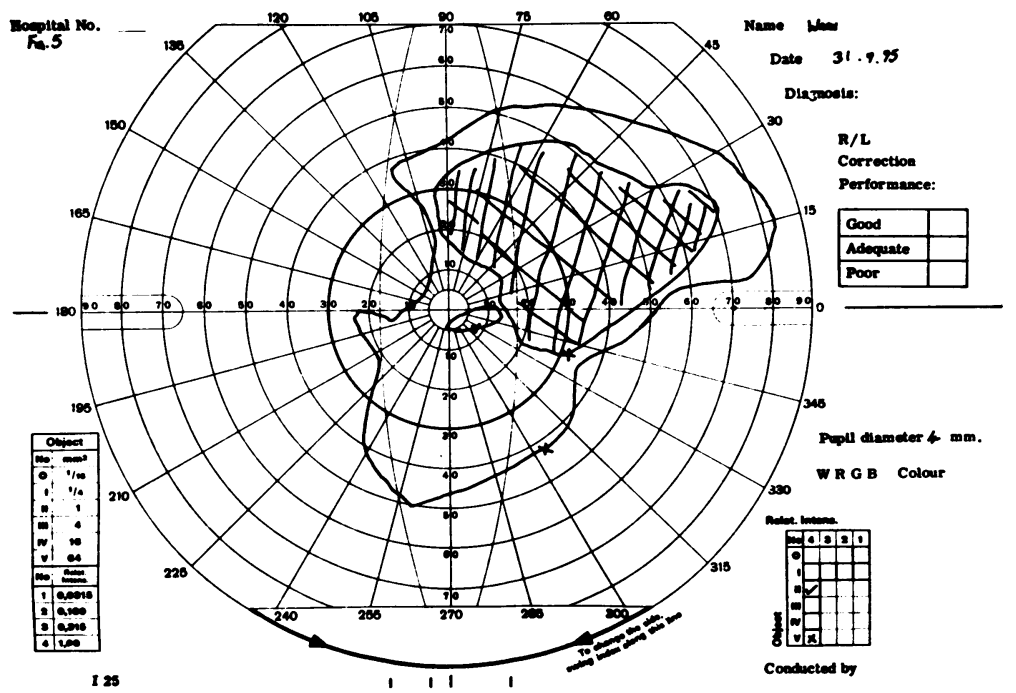

Fig. 3 Visual field in ischaemic type of CRVO showing marked constriction without treatment 


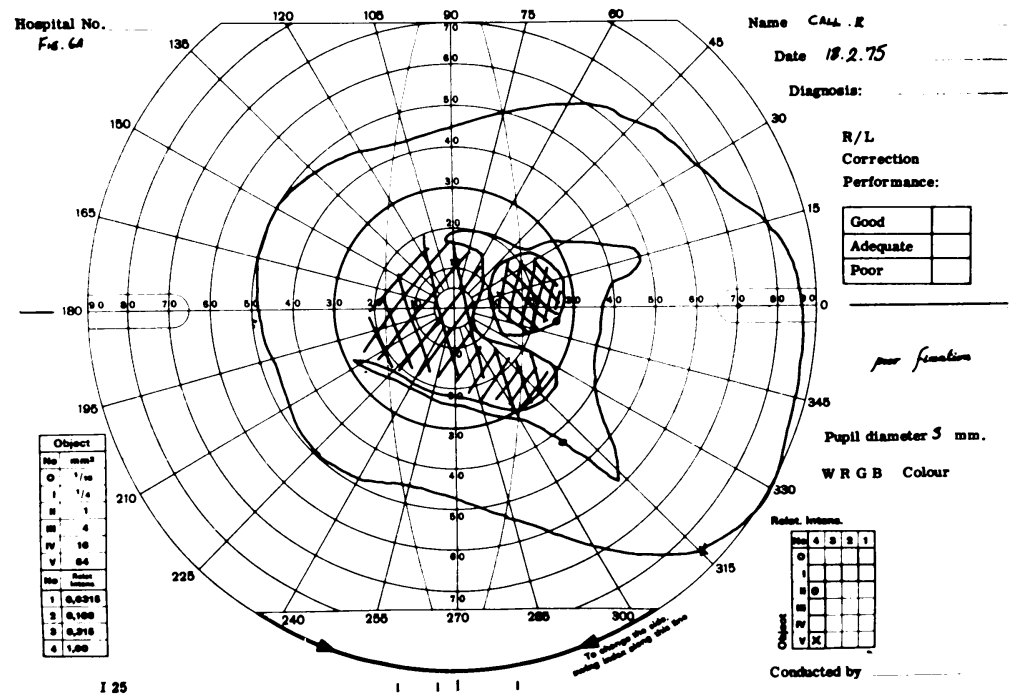

Fig. $4 a$ Visual field in ischaemic type of CRVO before photocoagulation with central scotoma but preservation of the peripheral field

pared with the other eye was also found (Fig. 5a). During the follow-up the central scotoma became smaller in both the untreated (Fig. 5b) and the treated cases, but in the treated eyes considerable constriction of the peripheral field was seen (Fig. 6b).

\section{IRIS NEOVASCULARISATION AND}

\section{NEOVASCULAR GLAUCOMA}

The diagnosis of rubeosis iridis was based on clinically visible neovascularisation. Iris neovascularisation was not seen in any of the eyes with a hyperpermeability-response, macular-oedema group.
However, it did occur after 27 months after the initial symptoms in 1 patient in this group, who at that time developed widespread capillary closure in the retinal periphery. Iris changes in the ischaemic group are summarised in Table 1.

In the treated group 5 out of 12 eyes with the ischaemic type of occlusion already had some rubeosis at entry into the trial. In 4 of these eyes rubeosis disappeared after photocoagulation and in 1 eye it decreased considerably (Fig. $7 a, b, c$ ). In contrast, in 2 eyes mild peripupillary neovascularisation appeared after treatment. None of the

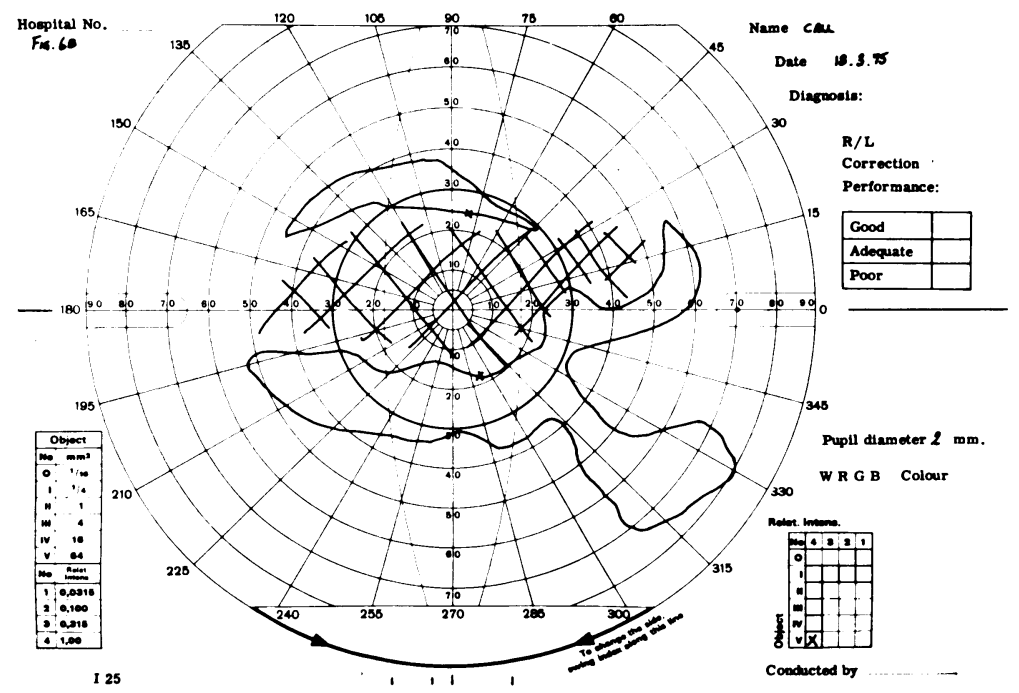

Fig. $4 b$ Same as Fig. 4a but after panretinal photocoagulation 


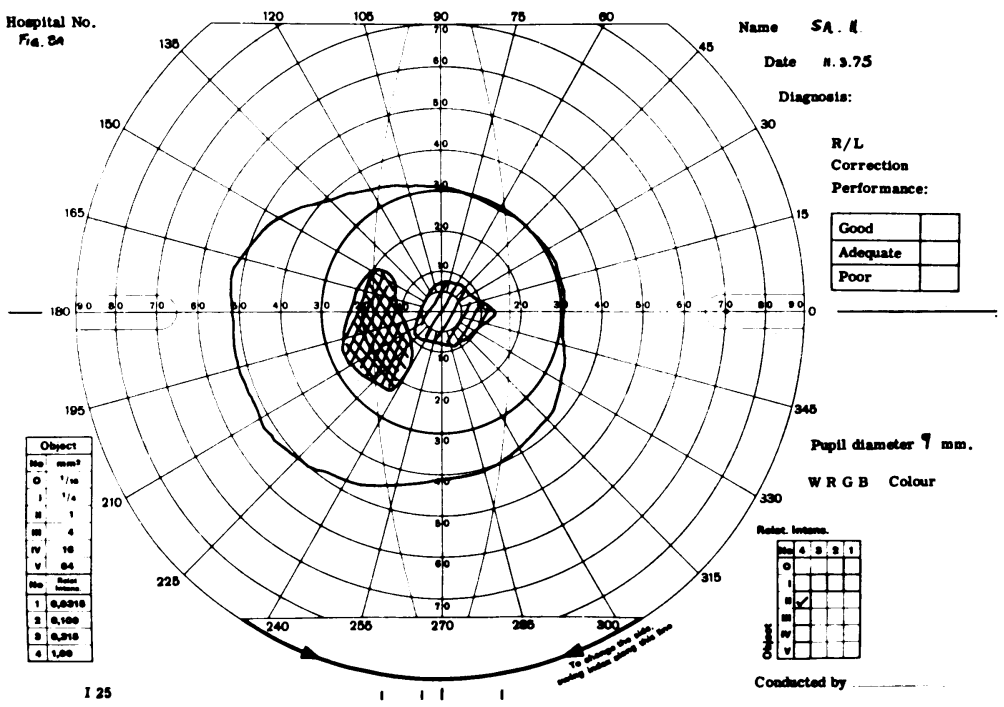

Fig. $5 a$ Visual field in macular oedema type of CRVO showing central scotoma and enlargement of blind spot

Table 1 The occurrence of iris neovascularisation and neovascular glaucoma in the ischaemic type of CRVO

\begin{tabular}{lll}
\hline Number of cases & Treated group & Untreated group \\
\cline { 2 - 3 } & 12 & 11 \\
\hline $\begin{array}{l}\text { Rubeosis present at the onset } \\
\text { of trial }\end{array}$ & 5 & 1 \\
$\begin{array}{l}\text { Rubeosis decreased or } \\
\text { disappeared during the follow- } \\
\text { up }\end{array}$ & 5 & - \\
$\begin{array}{l}\text { Rubeosis developed during the } \\
\text { follow-up }\end{array}$ & 2 & 5 \\
\begin{tabular}{l} 
Neovascular glaucoma developed \\
\hline
\end{tabular} & 2 \\
\hline
\end{tabular}

treated eyes have developed neovascular glaucoma.

In the untreated group 1 out of 11 eyes with the ischaemic type of occlusion had mild rubeosis at entry into trial. During the follow-up iris neovascularisation in this eye increased considerably centrally around the pupil, but the angle remained open and the intraocular pressure normal (Fig. $8 a, b, c, d)$. In 5 eyes iris neovascularisation developed during the follow-up period, and 2 of these progressed to neovascular glaucoma. One of the 3 eyes with normal intraocular pressure in spite of rubeosis developed extensive retinitis proliferans as well (Fig. 9a, $b$ ).

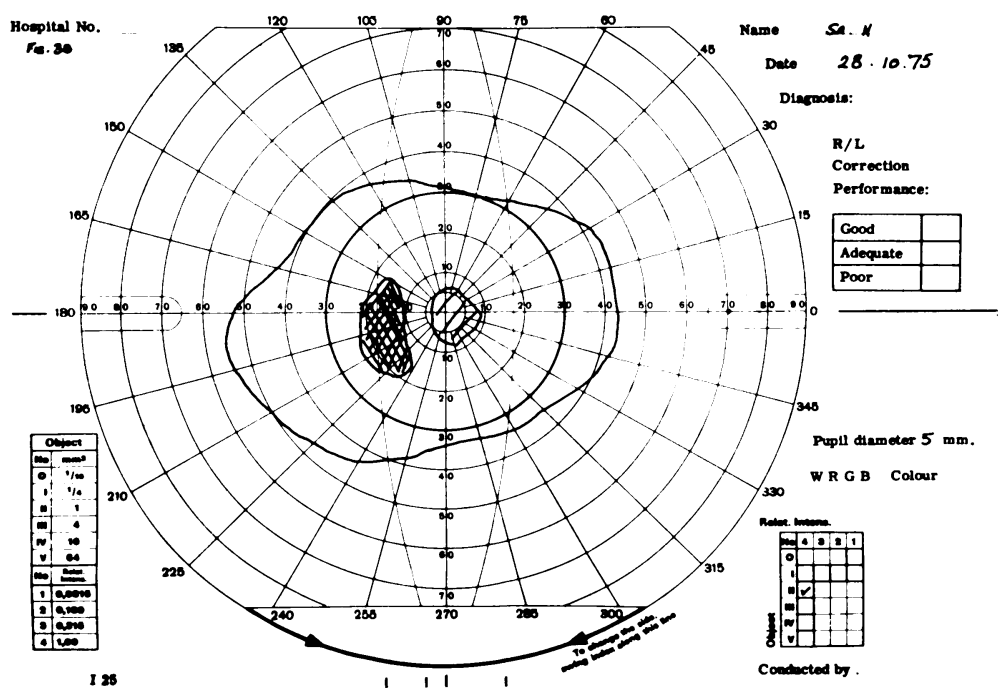

Fig. 5b Same as Fig. 5a but 7 months later without treatment 


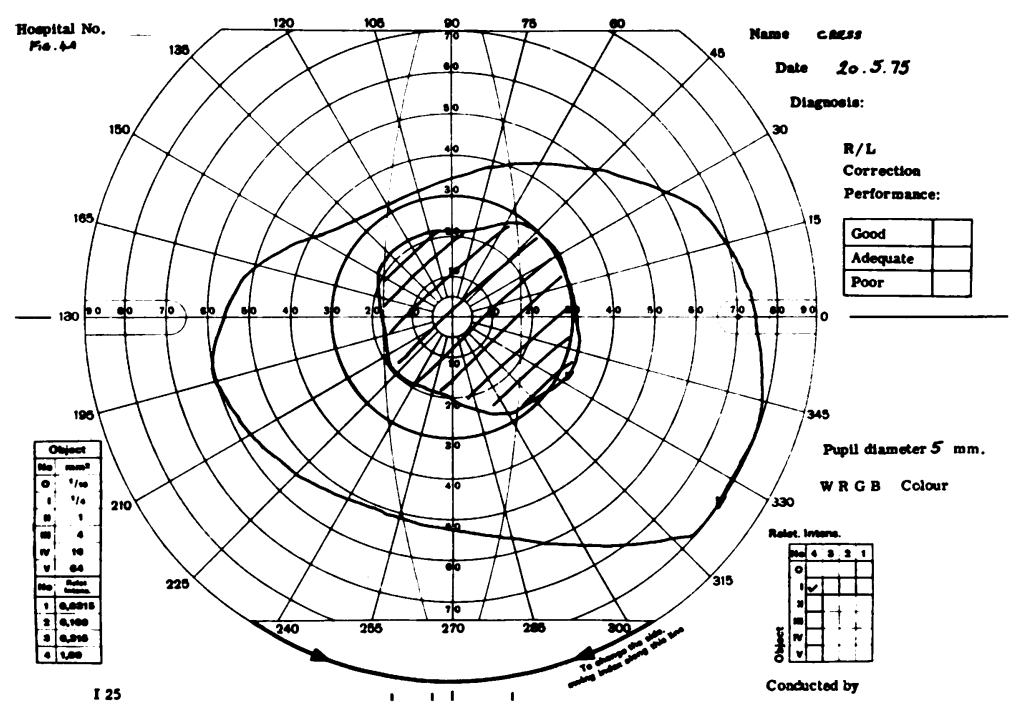

Fig. $6 a$ Visual field in macular oedema type of CRVO with large central scotoma

DISC AND RETINAL NEOVASCULARISATION No disc or retinal new vessels were found in the nonischaemic type of occlusion at any time of the follow-up.

Two out of the 12 treated eyes with the ischaemic type of occlusion had disc new vessels at the time of treatment (Table 2). In one eye the new vessels disappeared, the other progressed to more fibrosis and a traction retinal detachment of the upper temporal quadrant. At the time of treatment preretinal neovascularisation was found in 1 eye (Fig. 10a). In this case new vessels disappeared after
Table 2 Neovascular complication after 1 year follow-up in ischaemic type of CRVO

\begin{tabular}{|c|c|c|}
\hline & Treated group & Untreated group \\
\hline Number of cases & 12 & 11 \\
\hline Rubeosis iridis without glaucoma & 3 & 4 \\
\hline Neovascular glaucoma & - & 2 \\
\hline Disc new vessels & 1 & 5 \\
\hline Preretinal new vessels & 3 & 2 \\
\hline Vitreous haemorrhage & 1 & - \\
\hline
\end{tabular}

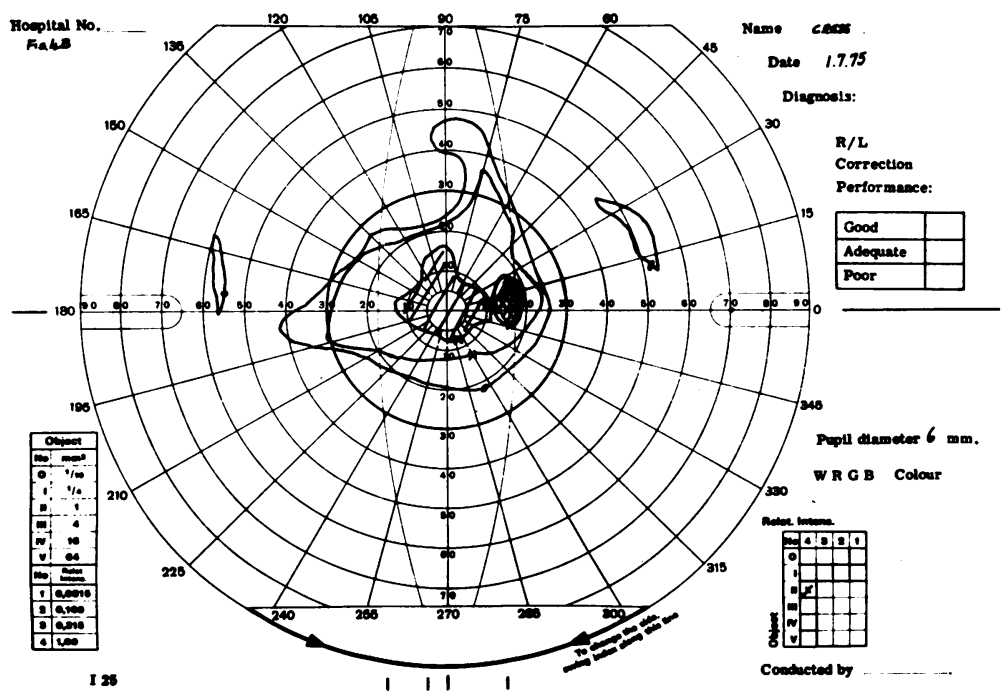

Fig. 6 bame as Fig. 6a but after panretinal photocoagulation showing decrease in central scotoma, but considerable constriction of peripheral field 


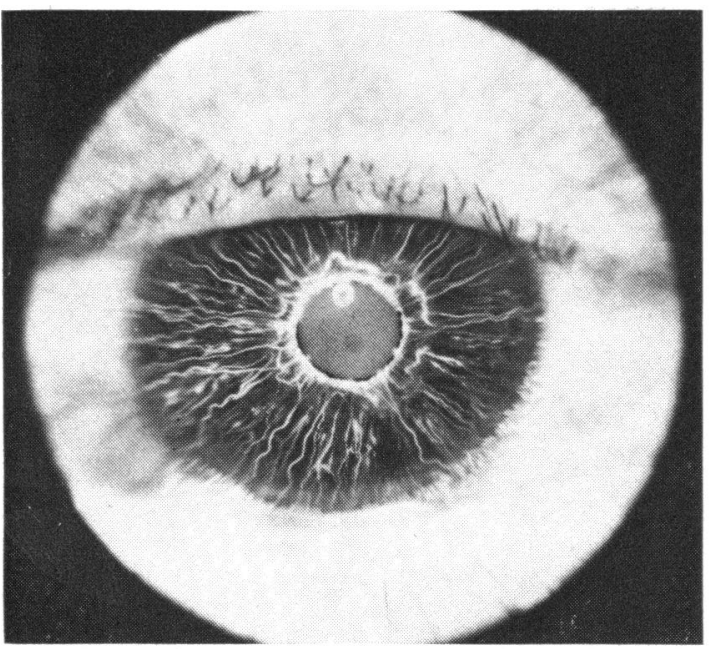

7a

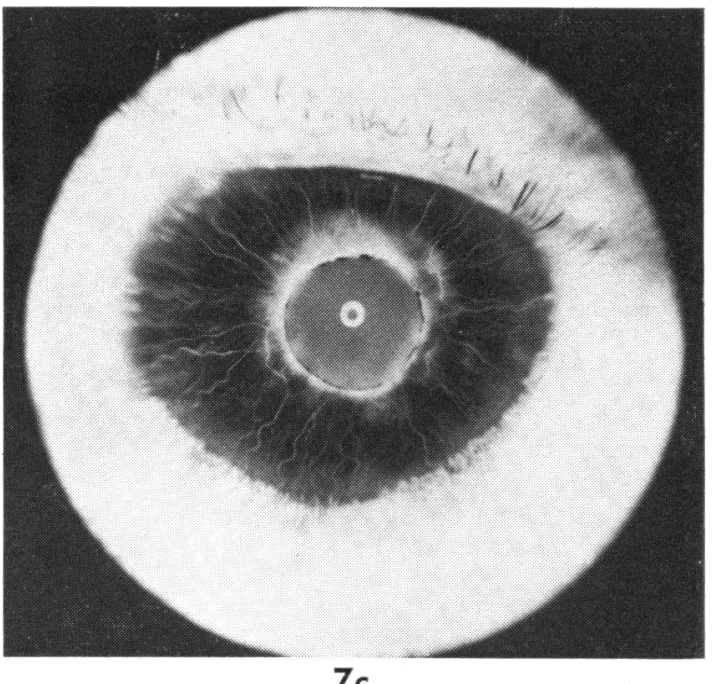

$7 c$

treatment (Fig. 10b). In 2 eyes these new vessels remained small along the main temporal vein and disc (Fig. 11), but in 1 eye preretinal neovascularisation has resulted in vitreous haemorrhage.

In the untreated group 5 out of the 11 eyes with the ischaemic type of occlusion have developed disc new vessels (Fig. 9b), resulting in secondary traction detachment of the retina in 2 . In the other 3 cases disc new vessels remained small and have not caused any further complications yet. All but one of the 5 eyes with disc new vessels developed iris new vessels (Fig. 9a, b), but only one developed neovascular glaucoma. In 2 of the 11 untreated eyes preretinal neovascularisation was found (Fig. 12); one of these developed disc new vessels as well. There were no vitreous haemorrhages from the new

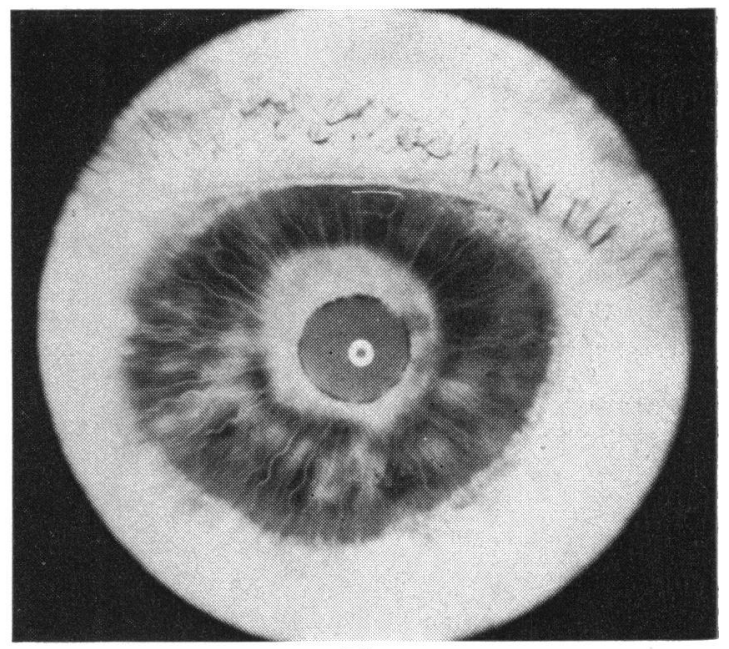

7b

Fig. $7 a$ and $b$ Ischaemic type of CRVO. Pretreatment iris fluorescein angiogram showing mild neovascularisation and leakage of dye

Fig. 7c Same as Fig. 7a and b, but 1 month after panretinal photocoagulation. Iris new vessels improved markedly

vessels in the untreated eyes during the period of follow-up.

Table 2 summarises the occurrence of all the neovascular complications after 1 year follow-up in the 12 treated and 11 untreated cases of the ischaemic type of occlusion. Because of the small number of cases the differences are not statistically significant, although it seems that neovascular glaucoma and disc neovascularisation were more common in the untreated eyes, whereas preretinal new vessels were equally common in the treated and untreated groups.

\section{MACULAR FINDINGS}

At the onset of the study some macular oedema with or without cystoid spaces and haemorrhages was 


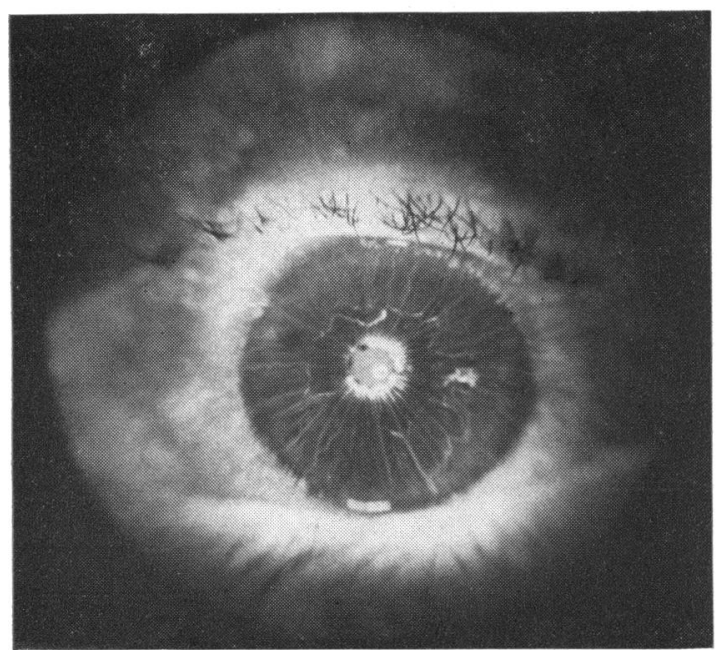

$8 \mathrm{a}$

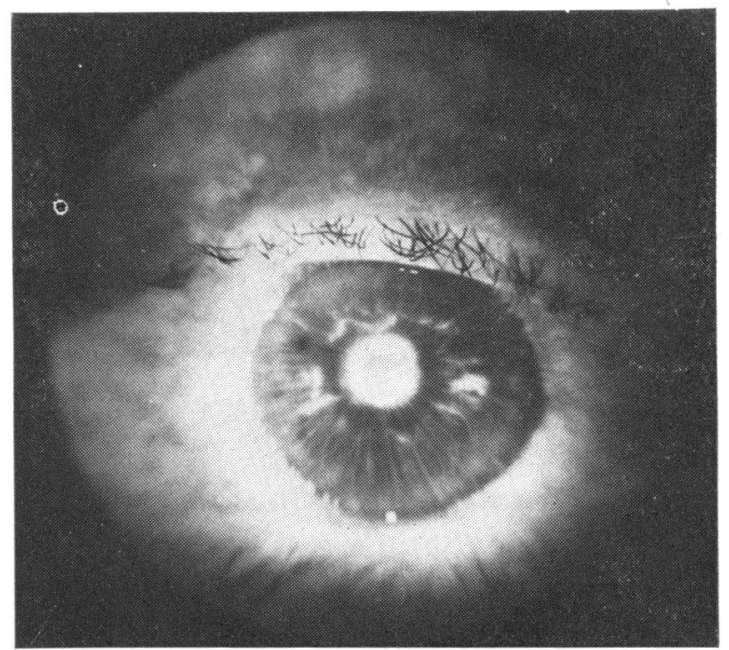

$8 \mathrm{~b}$

Fig. $8 a$ and $b$ Ischaemic type of CRVO, untreated eye. Mild iris neovascularisation at entry into the trial

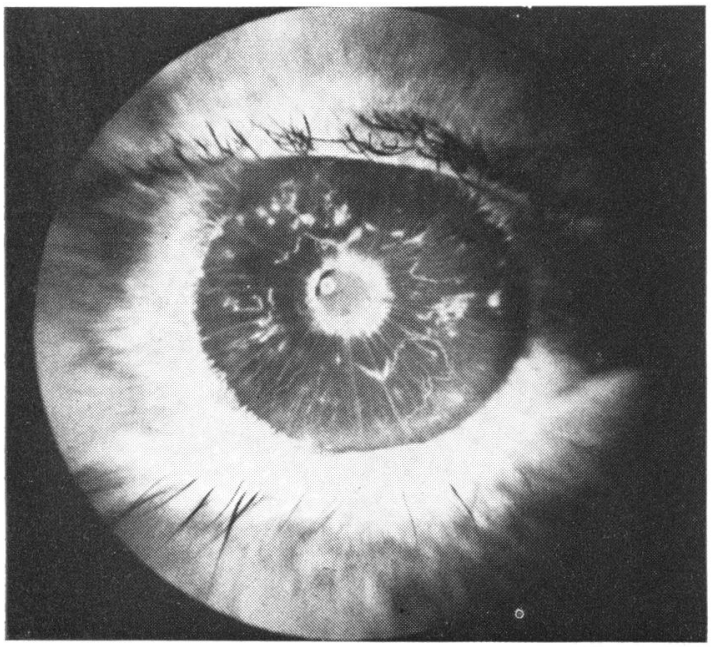

$8 c$

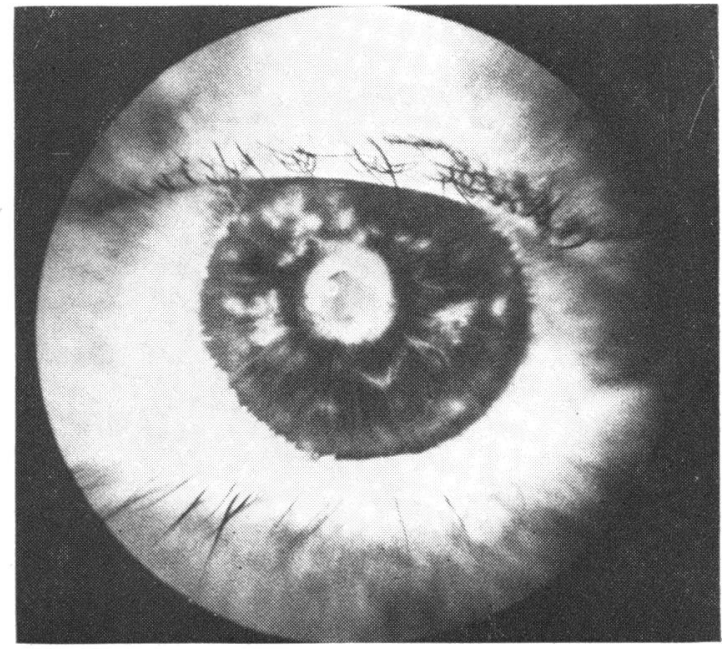

$8 \mathrm{~d}$

Fig. $8 c$ and $d$ Same as Fig. $8 \mathrm{a}$ and b, but after 3 months' follow-up showing progression of the iris neovascularisation

present in all cases. Table 3 summarises the final macular appearance in the various groups.

Macular changes in the 'non-ischaemic' type of occlusion were universal: in all the 12 treated eyes macular oedema decreased, but in 5 of them cystoid macular oedema persisted (Fig. 13, $a, b, c$ ) and in one eye a macular hole developed. In the other 6 eyes pigment epithelial changes and retinal atrophy appeared (Fig. 14, $a, b, c)$. Some decrease in macular oedema was also seen in all 13 untreated cases, but cystoid macular changes remained in 9 eyes. In 5 out of 13 untreated cases the macula became dry and pigment epithelial changes and retinal atrophy developed.

Macular changes also occurred in the ischaemic type of occlusion. In 2 out of 12 treated eyes macular oedema persisted, and in 6 eyes the macula became dry with pigment epithelial changes or subretinal scarring (Fig. 15). In 2 eyes preretinal fibrosis and macular traction developed (Fig. 16). One macula looked normal (in this case capillary closure did not affect the macular area), and in 1 eye the fundus could not be seen because of vitreous haemorrhage. In 3 out of 11 untreated eyes with the ischaemic type 


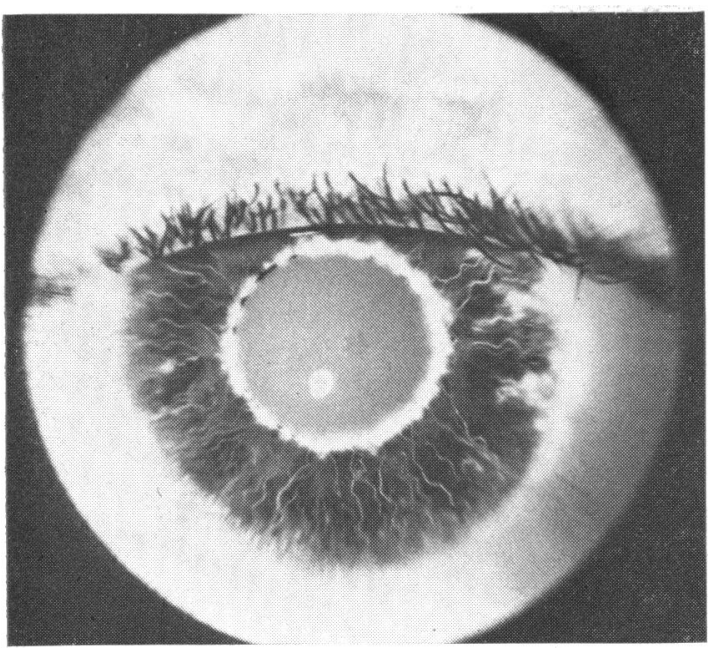

Fig. 9a Ischaemic type of CRVO untreated eye. Mild rubeosis iridis

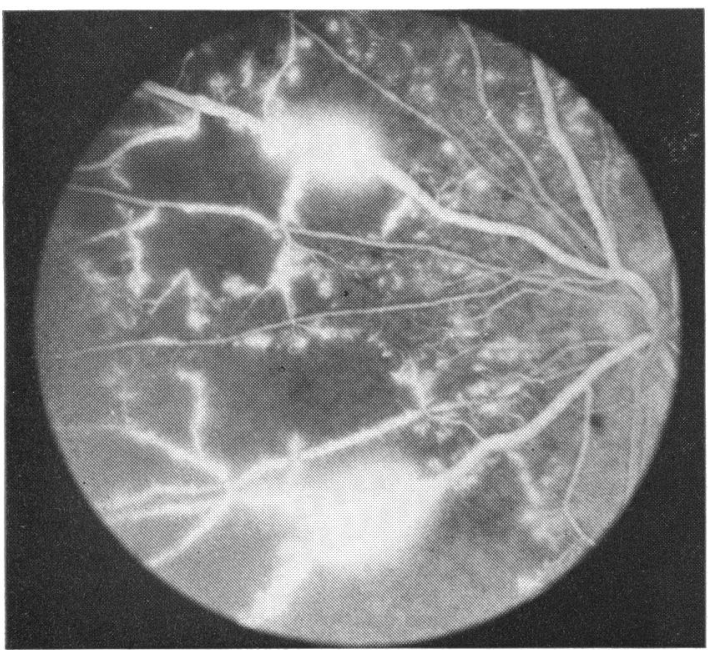

Fig. 10 a Preretinal new vessel formation in eye with extensive capillary closure in the nasal field

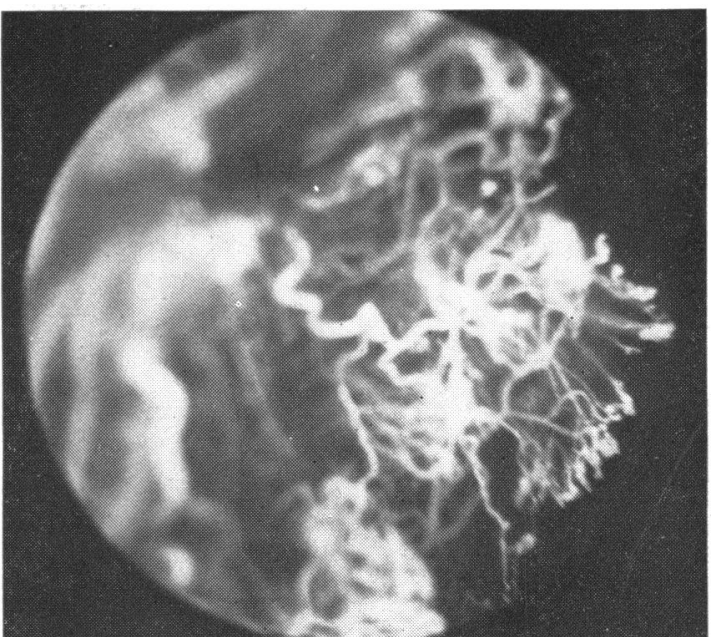

Fig. $9 b$ Same patient as Fig. 9a, but showing extensive new vessels formation on optic disc

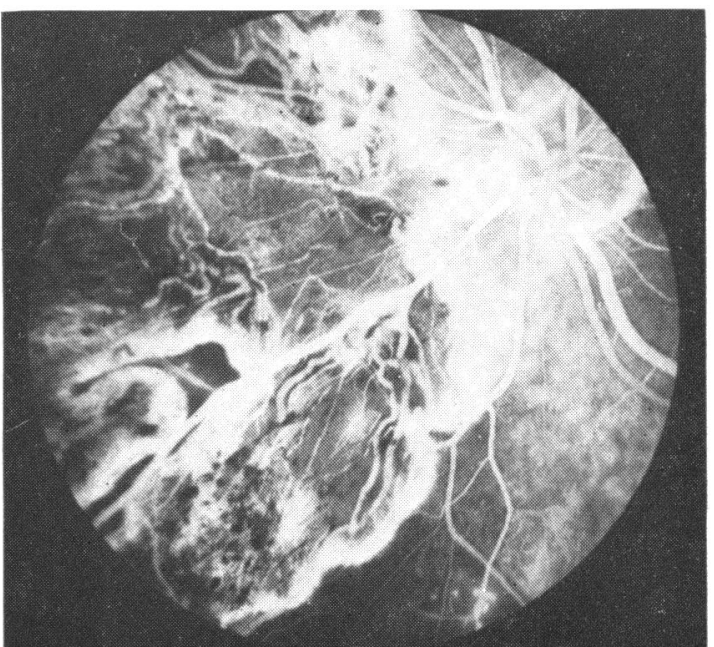

Fig. $10 \mathrm{~b}$ Same as Fig. 10a, but 1 year after photocoagulation of the non-perfused area, new vessels have regressed

Table 3 Macular appearance after 1 year follow-up in 24 treated and 24 untreated cases of CRVO

\begin{tabular}{lllll}
\hline \multirow{2}{*}{ Macula } & \multicolumn{2}{l}{ Treated group } & & \multicolumn{2}{l}{ Untreated group } \\
\cline { 2 - 5 } \cline { 3 - 5 } & $\begin{array}{l}\text { Non-ischaemic } \\
\text { type of CRVO }\end{array}$ & $\begin{array}{l}\text { Ischaemic } \\
\text { type of CRVO }\end{array}$ & $\begin{array}{l}\text { Non-ischaemic } \\
\text { type of CRVO }\end{array}$ & $\begin{array}{l}\text { Ischaemic } \\
\text { type of CRVO }\end{array}$ \\
\hline Total number of eyes & 12 & 12 & 13 & 11 \\
\hline Normal & - & 1 & - & - \\
Oedematous & 5 & 2 & 9 & 3 \\
Pigment epithelial changes and/or retinal atrophy & 7 & 6 & 4 & 4 \\
Preretinal fibrosis & - & 2 & - & 1 \\
Not visible (vitr. haem., neovas. glaucoma) & - & 1 & - & 3 \\
\hline
\end{tabular}




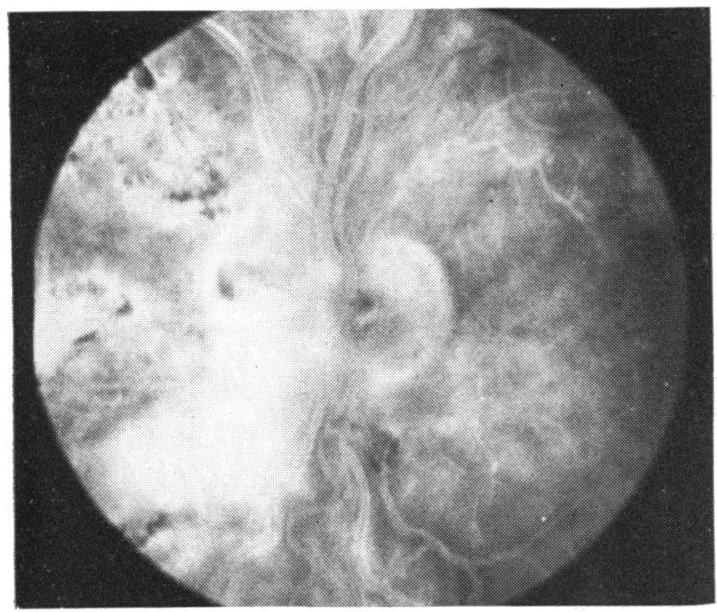

11

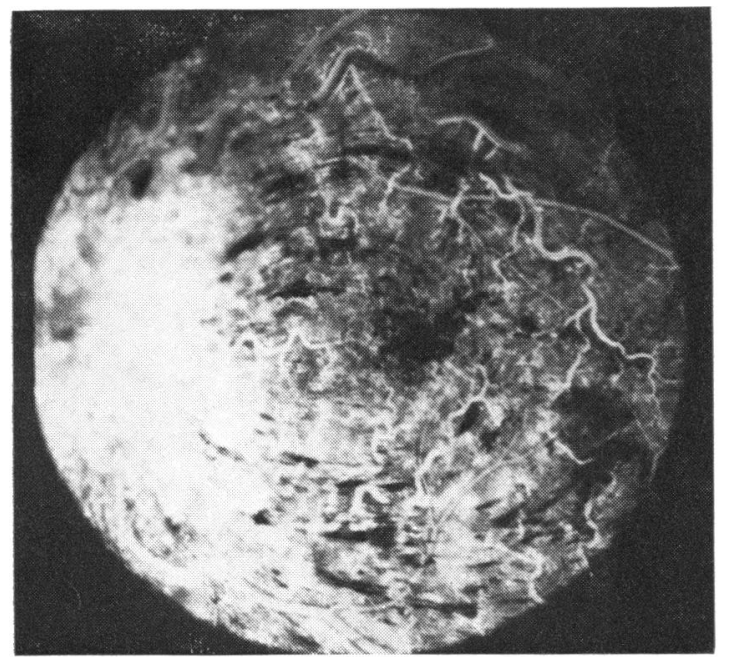

$13 a$

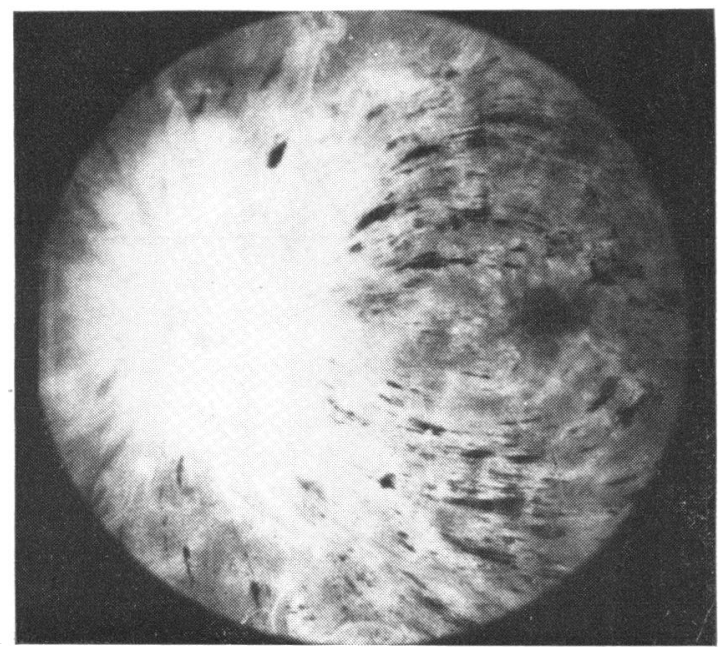

$13 b$

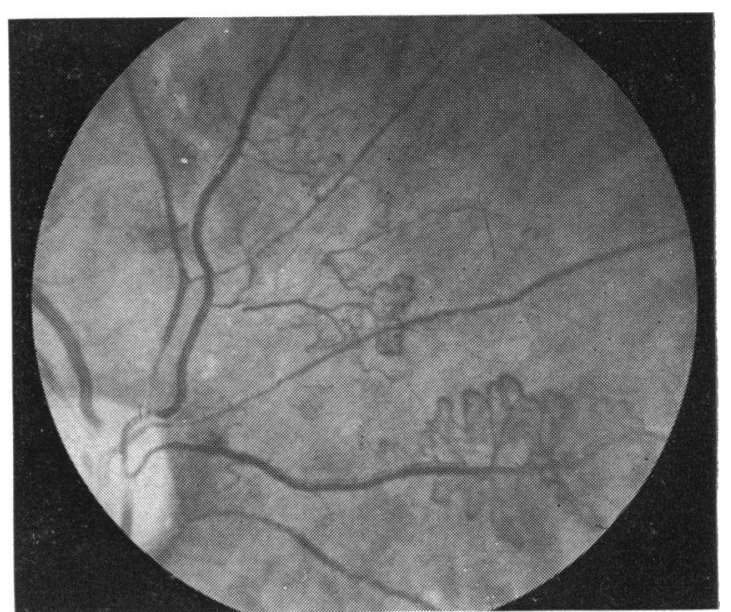

12

Fig. 11 Ischaemic CRVO. Small new vessels on optic disc developed in spite of photocoagulation

Fig. 12 Ischaemic CRVO, untreated eye. Several preretinal new vessels visible

Fig. $13 a$ and $b \quad$ Hyperpermeability type of CRVO. Pretreatment fuorescein angiograms with broken perifoveal capillary arcade and leakage of dye

Fig. 13c Same as Fig. 13a and b, but 1 year after photocoagulation with persistent fluorescein leakage and macular oedema

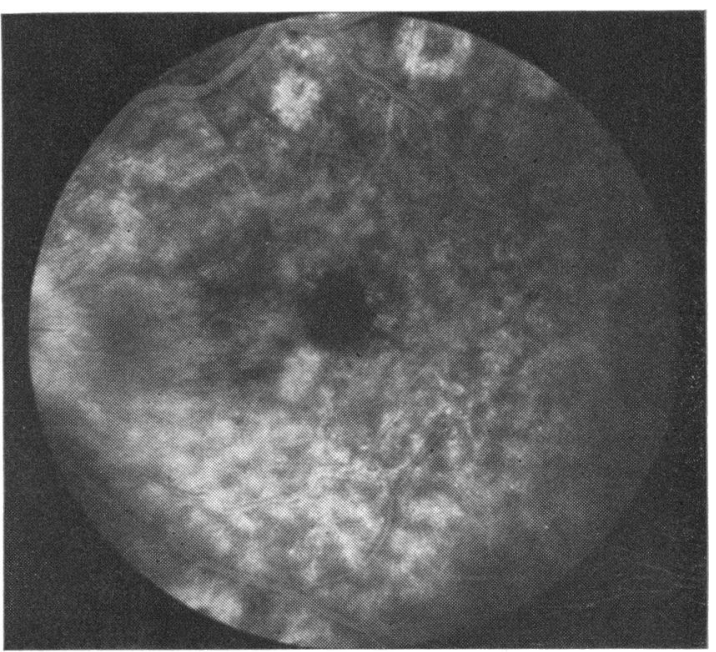

$13 c$

macular oedema




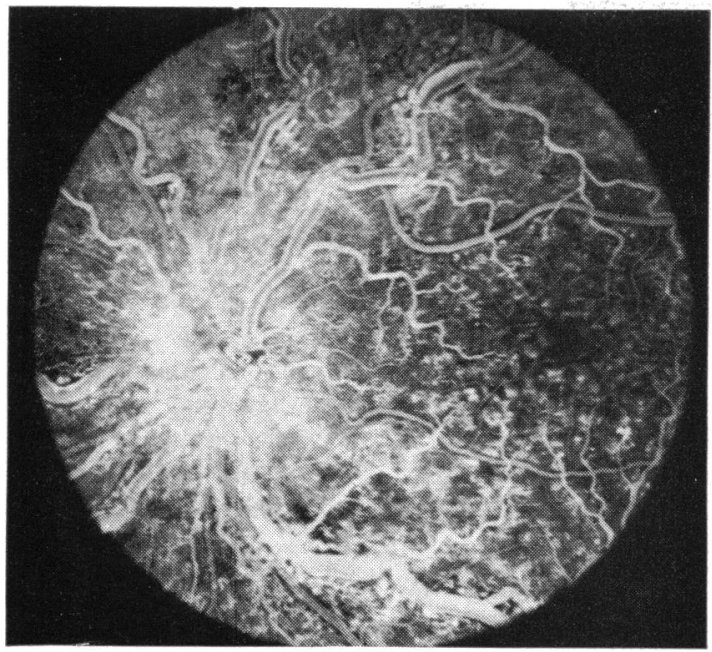

$14 a$

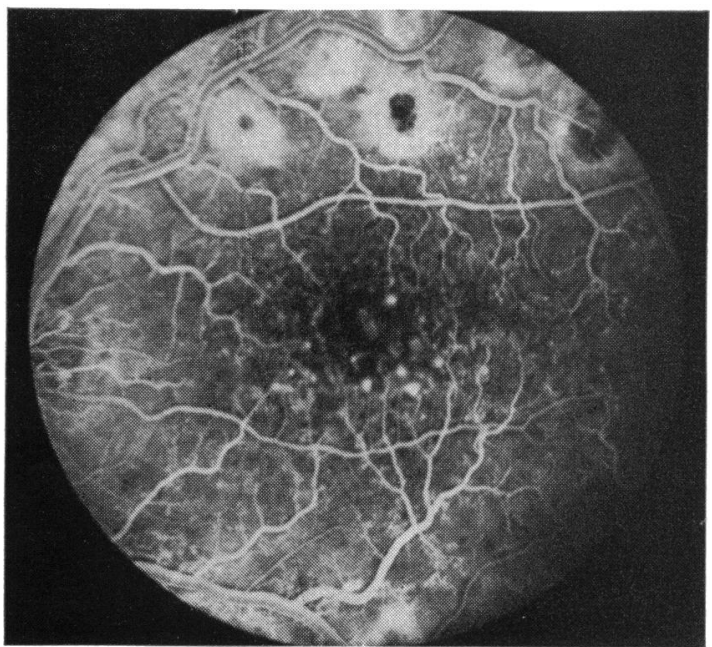

$14 c$

of occlusion diffuse macular oedema with or without cystoid spaces persisted throughout the follow-up, whereas in 4 eyes the macula became dry and atrophic with marked pigment epithelial changes and 1 case developed macular traction due to preretinal fibrosis. In 1 eye the macula was covered by large fronds of new vessels (Fig. 9b), and in 2 eyes, which developed neovascular glaucoma, the macula was not clearly visible at the latest examination.

\section{Discussion}

In a previous paper (Laatil.ainen and Kohner, 1976) we have shown that in the ischaemic type of CRVO prognosis is always poor. In those with the hyperpermeability response macular oedema from dilated

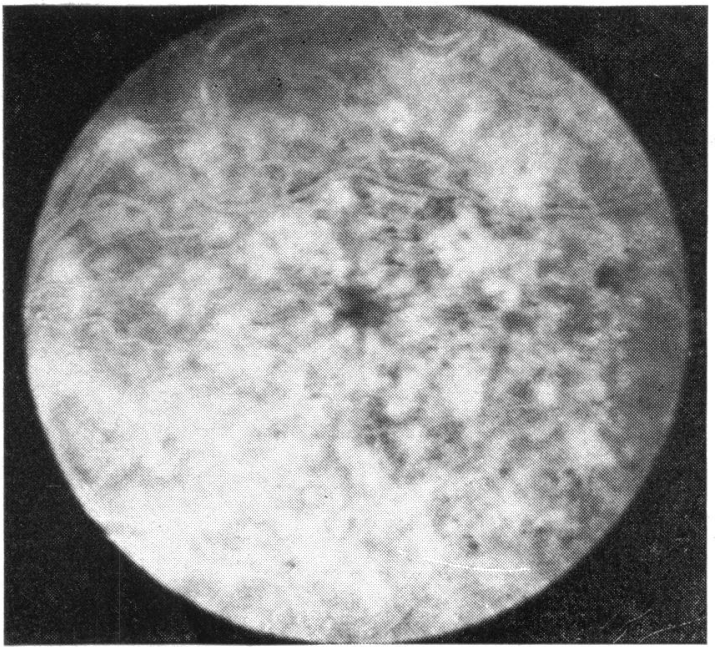

$14 b$

Fig. 14a and $b \quad$ Hyperpermeability type of CRVO. Pretreatment fluorescein angiogram with broken perifoveal capillary arcade and leakage of dye

Fig. 14c Same as Fig. 14a and b, but 1 year after photocoagulation. Macula dry with marked pigment changes

and leaky capillaries is the cause of visual loss.

In the ischaemic type of occlusion large areas of retina are non-perfused. In CRVO as in other vascular retinopathies retinal non-perfusion acts as a stimulus for neovascularisation. Therefore the rationale for photocoagulation therapy is to destroy non-perfused retina or at least reduce it. In these eyes the visual prognosis did not improve by photocoagulation, but the development of late neovascular complications, particularly rubeosis iridis, neovascular glaucoma, and probably disc neovascularisation, were reduced or prevented by panretinal photocoagulation. In some eyes photocoagulation also caused fundus and iris new vessels to regress. This was also noticed in a few cases of neovascular glaucoma, which were not included in this study but 


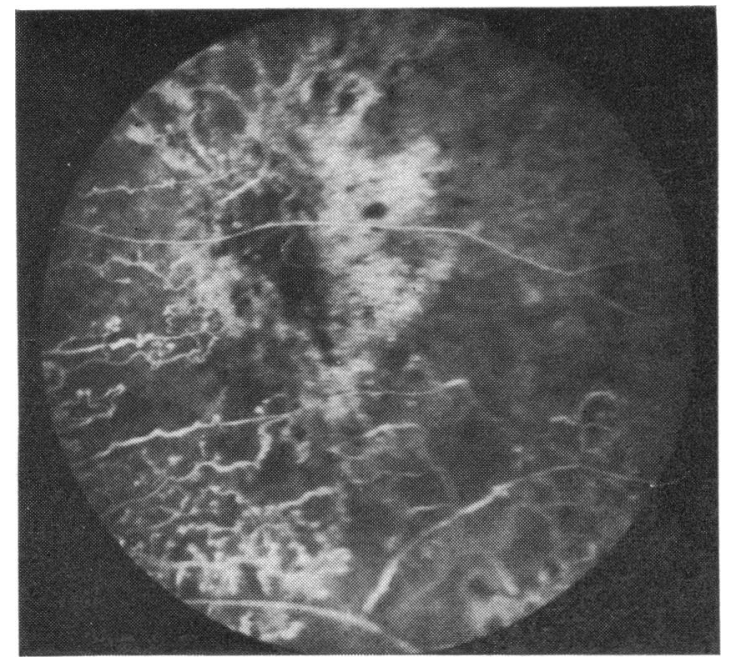

Fig. 15 Ischaemic CRVO. Avascular atrophic macula with subretinal scarring 1 year after photocoagulation, over 500 peripheral burns

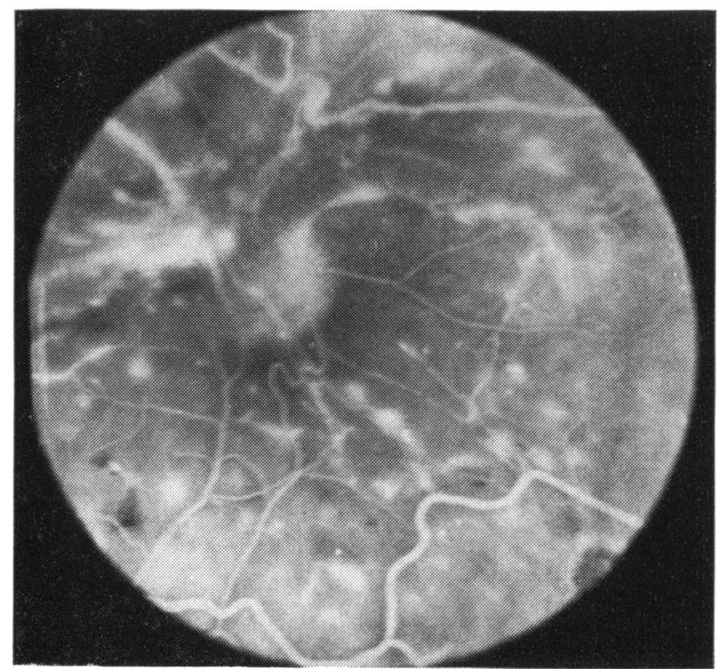

Fig. 16 Fundus photograph in ischaemic CRVO, massive preretinal fibrosis and traction on the macula developed after photocoagulation

which were similarly treated by xenon arc panretinal photocoagulation (Laatikainen, 1977).

Results of this study are in accordance with the preliminary results reported by May et al. (1976). In their randomised study on 20 eyes (10 treated, 10 untreated) 2 cases of neovascular glaucoma were found in the untreated group and none in the treated group. Theodossiadis (1976) also had 3 cases of neovascular glaucoma in the group of 18 un- treated eyes and none in the group of 25 treated eyes, but this study was not randomised. However, the number of cases with the ischaemic typc of occlusion and therefore in danger of developing neovascular glaucoma is not known in these two studies.

The rationale for photocoagulation therapy in the non-ischaemic type of CRVO is to obliterate leaking capillaries, thereby enabling reduction of the retinal oedema. The area of capillary damage may, however, be extensive and all the leaking capillaries cannot be photocoagulated, because the central macular area must be spared. It has also been suggested that by reducing the area of the viable retina by photocoagulation nourishment of the remaining retina might be improved (Campbell and Wise, 1973).

In this study the treatment was performed outside the temporal vascular arcade only, so that direct photocoagulation of the macular capillaries was not done. After 1 year follow-up the percentage of dry maculae was greater in the treated than in the untreated group; however, there was no difference in the central visual acuity between the treated and untreated eyes. It could be argued that treatment should have been inside the temporal arcade. However, in retinal branch vein occlusion Shilling (in press) found no difference between treated and untreated eyes, although he treated leaking vessels in the perimacular region using the laser.

The final visual outcome of both treated and control groups was in accordance with our earlier studies of untreated cases of non-ischaemic CRVO with macular oedema, which showed little change after the 3-month examination. No significant improvement in visual acuity in spite of drying out of the macular oedema was found either by Theodossiadis (1976) or May et al. (1976).

The duration of symptoms before treatment obviously influences final prognosis, because in the non-ischaemic type of CRVO spontaneous improvement during the first 3 months is common. Therefore in this study only eyes with a poor tendency to spontaneous recovery were included. Permanent macular damage may have resulted from the long period of macular oedema, and earlier treatment may produce better results.

In the non-ischaemic type of CRVO serious irreversible changes are usually restricted to the macular area. Therefore the peripheral visual field is usually not constricted. In those eyes the marked constriction of the fields caused by panretinal photocoagulation should be regarded as an unfavourable result of treatment.

On the basis of this study it is suggested that panretinal photocoagulation should be considered in cases with the ischaemic type of CRVO in order to prevent late neovascular complications, and in 
these eyes the treatment should be done as early as possible. On the other hand panretinal photocoagulation seems to have no value regarding visual prognosis in cases with the nonischaemic type of ocelusion and macular oedema.

We are grateful to all consultants at Moorfields Eye Hospital who referred patients to us.

The illustrations were prepared by Mr Melvyn Williams.

This work was supported by the Francis and Renée Hock Foundation.

\section{References}

Campbell, C. J., and Wise, G. N. (1973). Photocoagulation therapy of branch vein obstructions. American Journal of Ophthalmology, 75, 28-31.

Freyler, H., and Nichorlis St. (1974). Lichtkoagulation bei retinalen Venenthrombosen. Klinische Monatsblätter für Augenheilkunde, 165, 750-755.

Laatikainen, L. (1977). Preliminary report on the effect of retinal pan-photocoagulation on rubeosis iridis and neovascular glaucoma. British Journal of Ophthalmology, 61, 278-284.
Laatikainen, L., and Kohner, E. M. (1976). Fluorescein angiography and its prognostic significance in central retinal vein occlusion. British Journal of Ophthalmology, 60, 411-418.

May, D. R., Klein, M. L., and Peyman, G. A. (1976). A prospective study of xenon arc photocoagulation for central retinal vein occlusion. British Journal of Ophthalmology, 60, 816-818.

Oosterhuis, J. A., and Sedney, S. C. (1975). Photocoagulation in retinal thrombosis. Ophthalmologica, 171, 365379.

Sedney, S. C. (1976). Photocoagulation in retinal vein occlusion. Documenta Ophthalmologica, 40, 1-241.

Shilling, J. (in Press). Photocoagulation in retinal branch vein occlusion: a preliminary report.

Theodossiadis, G. (1976). A comparative study of treated and non-treated cases of central retinal vein occlusion. Documenta Ophthalmologica Proc. Ser. No. 9, 165-172.

Theodossiadis, G., Charamis, J., and Velissaropoulos, P. (1974). Behandlungsergebnisse der Lichtkoagulation bei Ast- und Zentralvenenverschluss. Klinische Monatsblätter für Augenheilkunde, 164, 713-721.

Wetzig, P. C., and Thatcher, D. B. (1974). The treatment of acute and chronic central venous occlusion by light coagulation. Moderne Probleme der Opthhalmologie, 12, 247-253.

Zweng, H. C., Fahrenbrush, R. C., and Little, H. L. (1974). Argon laser photocoagulation in the treatment of retinal vein occlusion. Moderne Probleme der Ophthalmologie, 12, 261-270. 